\title{
CORRELATION ANALYSIS BASED ON QUANTUM CHEMICAL PARAMETERS IN THE STUDY OF VDAC REGULATORS CONTAINING 4-HYDROXY-3,5-DI-TERT-BUTYL PHENYL GROUP
}

\author{
D.I. Pozdnyakov, M.V. Chernikov, A.V. Mamleev
}

Department of Pharmacology with a course of Clinical Pharmacology, Pyatigorsk Medical and Pharmaceutical Institute-branch of Volgograd state medical university,

357532, Russia, Stavropol Territory, Pyatigorsk, Kalinina ave., 11.

DOI: 10.19163/MedChemRussia2021-2021-177

E-mail.Pozdniackow.dmitry@yandex.ru

In cerebral ischemia, VDAC channels regulate the formation of the mitochondrial transitional permeability pore and, accordingly, the processes of cellular bioenergetics and apoptosis, which makes them a promising pharmacotherapeutic target [1]. This study focused on the study of the VDAC-regulatory potential of compounds having a 4-hydroxy3,5-di-tret-butyl phenyl group in their structure and assessing the dependence of the level of pharmacological activity of these compounds on the quantum-chemical and stereometric parameters of molecules. A total of 7 compounds were analyzed.

Table 1

Structure of test-substances

\begin{tabular}{|c|l|l|l|l|l|l|}
\hline MitoFL1 & MitoFL2 & MitoPYR1 & MitoPYR2 & Mito FC1 & Mito FC2 & ATACL \\
\hline & & & & & &
\end{tabular}

As a pathology model, a model of permanent focal cerebral ischemia in Wistar rats was chosen as reflecting the spectrum of negative changes in cell mitochondria mediated by impaired VDAC activity [2]. The test substances were administered at a dose of $50 \mathrm{mg} / \mathrm{kg}$ per os after simulating cerebral ischemia for 3 days, after which changes in the activity of VDAC channels were determined in the brain tissues. As a result, it was found that the use of all studied compounds contributed to a decrease in the activity of VDAC channels, and the level of pharmacological activity of the evaluated substances depended to a greater extent on the length of the molecule $(r=0.97509)$; molecular area $(r=0.89957)$ and molecule volume $(r=0.85641)$ and practically did not depend on the heat of formation $(r=0.07892)$, dipole moment $(r$ $=0.03498)$ and normal gradient $(r=0.03626)$.

\section{References}

[1] Fang D, Maldonado EN. VDAC Adv Cancer Res. 2018; 138: 41-69.

[2] Liu HT, Tashmukhamedov BA, Inoue H, Okada Y, Sabirov RZ. Glia. 2006; 54 (5): 343-57. 